\title{
Design of Pokkali Paddy Harvester
}

\author{
H.K. Venkata Reddy, Chandrashekar and P.R. Jayan \\ Department of Farm Machinery and Power Engineering \\ Kelappaji College of Agricultural Engineering and Technology, Tavanur -679 573, India \\ E-mail: venkatreddy.1709@gmail.com
}

\begin{abstract}
The term 'Pokkali' used in the common parlor refers to a salt tolerant traditional rice cultivar grown in the coastal saline soils of Kerala. The conventional method of harvesting of pokkali paddy crop by using sickles. The various farming operations in Pokkali paddy cultivation, the harvesting is done by women labourers by walking on the swampy and marshy inundated paddy fields at waist-deep water, which is laborious, tedious and cumbersome. Though a number of paddy combine harvesters are commercially available, none cannot be used in such marshy water logged areas for harvesting paddy. Hence, a power operated floating harvester with provisions for harvesting and conveying the ear heads (panicles) of submerged paddy. Design of harvester is sequentially carried out for the floating barge, harvesting unit and hydraulic system. The capacity of the hydraulic tank was 150 litres and double acting hydraulic pump has 61.0 min $^{-1}$. Harvesting unit of the harvester consists of a reel, cutter bar and conveyor. The overall size of the harvester is $6.2 \times 1.7 \times 1.7 \mathrm{~m}$ with a total weight of about $1700 \mathrm{~kg}$.
\end{abstract}

Keywords: Harvester, Hydraulic, Pokkali paddy, Water logged, Saline

The Pokkali field is a unique eco system prevailing in the coastal tract of Kerala with rich bio diversity and amazing capacity to produce organic rice and shrimp alternatively. Rice is grown during non-saline period and the farmers carry out shrimp culture during the saline phase with both having unique symbiotic benefits. Rice plants get their nutrients from the left over of the shrimps and the shrimps in turn, feed on the stalks and decaying remnants of the rice crop. Neither chemical fertilizers nor insecticides and pesticides are used. The usual ploughing and transplantation are not required for Pokkali. Pokkali areas lie in Trissur, Ernakulum and Alappuzha districts covering a total area of 8500 ha. In more than $90 \%$ of the single cropped lands, rice cultivation is done during the low saline phase from May-June to September-October. The traditional prawn filtration is taken up during the high saline phase which sets in December-January. Generally manuring and plant protection operations are not necessary for pokkali farming systems. The crop matures at about 120 days. The ear heads alone are harvested, leaving the straw behind. The average yield of rice with traditional rice varieties is $1500 \mathrm{~kg} \mathrm{ha}^{-1}$. The conventional method of harvesting of pokkali paddy crop by using sickles. The various farming operations in Pokkali paddy cultivation, the harvesting is done by women labourers by walking on the swampy and marshy inundated paddy fields at waist-deep water, which is laborious, tedious and cumbersome. Jayan and Sathyanathan (2010) conducted a study on overview of farming practices in the water logged areas of Kerala. Studies reviewed that the fields are situated below the mean sea level and having the problems of water- logging and have no addition of chemical pesticides or fertilizers in the Pokkali rice fields which make them different from the other farming practices in Kerala.Bautista et al (2005) designed a rotary cutting reaper for rice. Their purpose was replacing the reciprocating cutter bar assembly with a rotary cutting system borrowed from grass cutters. These rotary cutters required fewer blades and less manufacturing. Study physical and mechanical properties of Pokkali soil and design features of the Pokkali paddy harvester.

\section{MATERIAL AND METHODS}

The Pokkali paddy harvester is designed for harvesting and collecting of panicle (ear head) of the paddy, while moving through the waist depth water. It is also designed as an amphibian harvester where it can traverse in water and land or both along with the harvesting operation.

Design of floating barge: Floating barge is an air filled structure providing buoyancy. The floats contain a lot of reserve buoyancy and allow to carry loads. Floating body is partially immersed in a fluid that experiences an upward force equal to the weight of the fluid displaced. The float be constructed with MS sheet metal (Gauge-12) of thickness 2.0 $\mathrm{mm}$ as that of the original prototype. But, each float should have dimensions of $3.0 \times 0.45 \times 0.6 \mathrm{~m}$. The two floats have to be provided on either sides of Pokkali paddy harvester. In addition to the two floats, a separate air chamber be provided in between the two floats. The chamber also be constructed with MS sheet metal of thickness $2 \mathrm{~mm}$ and of size $3.0 \times 0.6 \mathrm{x}$ $0.4 \mathrm{~m}$. 
Traction belt: Tractive force is the ability of a vehicle tractive element to generate sufficient forces to overcome the soil resistance. Tractive belts made of polypropylene having a thickness of $10 \mathrm{~mm}$ and size $6.60 \times 0.45 \mathrm{~m}$ is provided to generate enough traction.

Paddle: Paddle is a mechanical device for propelling a floating machine attached to the rear side. A revolving shaft attached with eight broad and angle blades is provided. It should be connected to hydraulic motor (MAT 500SH) through chain drive. The size of the paddle is $0.4 \times 0.75 \mathrm{~m}$.

Design of hydraulic system: Hydraulic tank is closed type reservoir which is the integral part of a system and reservoir tank act as the main oil container for the entire system. The reservoir is designed in such a way that to drain the old, used oil and contaminants from the tank (Fig. 1). Oil filter is placed on the top of the hydraulic tank and same is connected to return line hydraulic hoses so as to filter the contaminants in the oil. Sight and level gauges offer an inside view of fluid levels in the hydraulic tank. Based on the design and requirement of oil for the operation an around 150 litre capacity tank was fabricated and placed with good structural support in back of the operator seat. The overall dimension of the hydraulic tank is $0.5 \times 0.6 \times 0.5 \mathrm{~m}$. Hydraulic pump is constant volume of fixed displacement pump and can work $61 / \mathrm{min}^{-1}$. They are relatively quiet and of simple construction. The pump is coupled to and driven by the prime mover of the system. The inlet side of the pump is connected to the reservoir: the outlet or pressure side is connected to the direction control valve and thus to rest of the system. Hydraulic motor used here is gerotor which is coupled with the gear box for rotation of complete assembly up to $360^{\circ}$ on both the sides. Hydraulic motors can be instantly started, stopped, or reversed under any degree of load; they can be stalled by overload without damage.

The most familiar double acting cylinder is the single rod end is used to lift the front conveyor along with cutter bar and reel to the operational height. This type of cylinder provides power in both directions, with a pressure port at either end. In total there are five numbers of motors are used for the operations. In that two motors are fixed as floats in the left and right side. The two numbers of hydraulic motors are used as front and centre conveyor and one motor for the cutter bar operators at the time of operation. The diameter of the cylinder bore and piston are $40 \mathrm{~mm}$ and $30 \mathrm{~mm}$. Seamless tubes with high wall thickness, higher tensile strength, better bending quality, etc. are some of the specific properties which make such tubes most suitable for use in many high pressure hydraulic systems. Hence, for the operation of floating harvester the seamless pipes with two size (22 OD/18 ID and 16 OD/12 ID). The 22 OD/18 ID pipes are used for inlet and outlet of hydraulic oil and 16 OD/12 ID pipes were used for the MAT 500SH hydraulic motors. The arrangements are made in such a way that all the operations like lifting and rotation can be done by the operator at the time of operation itself.

Design of harvesting unit: Harvesting unit of the Pokkali paddy harvester consist of a reel, cutter bar and conveyor.

Reel: Reel delivers the stalks to the cutting mechanism. It holds the crop upright during cutting and delivers the cut stalks to the front conveyor (Fig. 2). It has a pentagonal frame fitted with five bats of length $120 \mathrm{~cm}$ fixed at a uniform spacing of $30 \mathrm{~cm}$. The diameter of each bat shall be $5 \mathrm{~cm}$. A total of eight fingers, each would and firmly at uniform intervals of 15 $\mathrm{cm}$. The reel assembly can be operated by a hydraulic motor (MR50) through chain drive. The design of the reel can be made according to the reel position with respect to cutter bar, reel speed with respect to forward speed, delivering the stalk to the cutting mechanism with minimum losses, holding the stalk upright while cutting and delivering the stalk to the conveyor. Also, the absolute velocity of the reel should be greater than the forward speed of the harvester.

The reel index was calculated based on the standard design procedures:

Reel index or velocity ratio $\left(\lambda_{i}\right)$ for reels is given by (Kanafojski and Karwowski, 1976):

$$
\lambda_{i}=\frac{u_{t}}{v_{m}}
$$

Where: $u_{t}=$ tangential velocity of tip of the bats, $\mathrm{m} \mathrm{s}^{-1}$

$\mathrm{v}_{\mathrm{m}}=$ forward velocity, $\mathrm{m} \mathrm{s}^{-1}$

Cutter bar: Cutter bar shall be operated by a hydraulic motor (MR50) through a crank pitman. A reciprocating type cutter bar of $1.2 \mathrm{~m}$ length having 16 knife sections, each having a stroke of $76.2 \mathrm{~mm}$ shall be provided. In order to avoid slipping off the stalks serrated knife sections were attached with the cutter bar. The pitch of serrated knife sections selected has to be two times smaller than the diameter of paddy stalk. Accordingly the pitch provided was $1.2 \mathrm{~mm}$. The velocity of knife section shall be $0.54 \mathrm{~m} \mathrm{~s}^{-1}$ at a forward speed of $1.5 \mathrm{~km}$ $\mathrm{hr}^{-1}$. Design of the cutter bar was carried out for finding the optimum speed of knife sections and number of knife sections based:

The velocity of knife section is expressed as: $V_{k}=R \times V_{m}$

Where: $\quad V_{k}=$ Average knife velocity, $\mathrm{m} \mathrm{s}^{-1}$

$\mathrm{V}_{\mathrm{m}}=$ Forward speed of harvester, $\mathrm{m} \mathrm{s}^{-1}$

$\mathrm{R}=$ Velocity ratio

The value of $R$ shall be in the range of between 1.3 to 1.4 with available cutter knife (Basal, 1989).

Taking $R=1.3$ and $V m=0.416 \mathrm{~m} \mathrm{~s}^{-1}\left(1.5 \mathrm{~km} \mathrm{~h}^{-1}\right)$ and putting values in above equation.

$$
\begin{aligned}
& V_{k}=1.3 \times 0.416 \\
& V_{k}=0.54 \mathrm{~m} \mathrm{~s}^{-1}
\end{aligned}
$$


Front conveyor: The crop cut by the cutter bar is conveyed to the conveyor for easy collection. It is made of $3.0 \mathrm{~mm}$ polypropylene sheet with equidistantly spaced rubber bars. The conveyor has to convey the bunch of cut crop continuously without blockage. It can be operated by a hydraulic motor $\mathrm{MAH}-400 \mathrm{CB}$ through the driving roller. This roller actuates the motion of the conveyor. The driven roller provided at the tail end, trails the conveyor forward and ensures continuous movement. The length of the conveyor belt shall be $1.7 \times 0.6 \mathrm{~m}$. The conveyor belt has to be wrapped over two rollers of $100 \mathrm{~mm}$ diameter and fixed on plummer blocks to stretch it firmly.

Speed of conveyor belt: For lugged belt conveyor the belt speed is given by

$$
V_{b}=\pi \frac{D_{P N P}}{60}
$$

Length of conveyor belt:It is calculated based on length of platform required for supporting the crop.Hence, centre to centre distance $(C)$ between driving and driven roller is provided as $1.7 \mathrm{~m}$.

The length of belt is given by

$$
\begin{aligned}
& L=2 C+\pi \frac{(D+d)}{2}+\frac{(D+d)^{2}}{4 C} \\
& =2 \times 1.7+3.142 \frac{(0.1+0.1)}{2}+\frac{(0.1+0.1)^{2}}{4 \times 1.7} \\
& =3.71 \mathrm{~m}
\end{aligned}
$$

Pitch of lugs: According to Devnani (1985), number of lugs on conveyor belt is

$$
\mathrm{N}=\frac{\mathrm{L}}{\mathrm{P}}
$$

Centre conveyor: The crop is conveyed from the front conveyor to the centre conveyor for easy collection and storage of the ear heads. It shall be made of $3.0 \mathrm{~mm}$ polypropylene sheet. The conveyor has to convey the bunch of cut crops. It shall be operated by a hydraulic motor MAH$400 \mathrm{CB}$ through the driving roller. The length of the conveyor belt shall be $3.7 \times 0.6 \mathrm{~m}$. The conveyor belt has to be wrapped over two rollers of $100 \mathrm{~mm}$ diameter, which should be fixed on plummer blocks to stretch firmly.

Length of conveyor belt: It is calculated based on length of horizontal platform required for supporting the crop. Hence, centre to centre distance $(\mathrm{C})$ between driving and driven roller is provided as $3.7 \mathrm{~m}$. The length of belt is given by

$$
L=2 C+\pi \frac{(D+d)}{2}+\frac{(D+d)^{2}}{4 C}
$$

Prime mover: The capacity to meet the power requirement for harvesting is taken into consideration for the selection of the prime mower. The total weight of the Pokkali paddy harvester comes around $1700 \mathrm{~kg}$. In order to operate cutter bar, reel assembly, front conveyor, centre conveyor and float with hydraulic motors and then to lift the front conveyor with

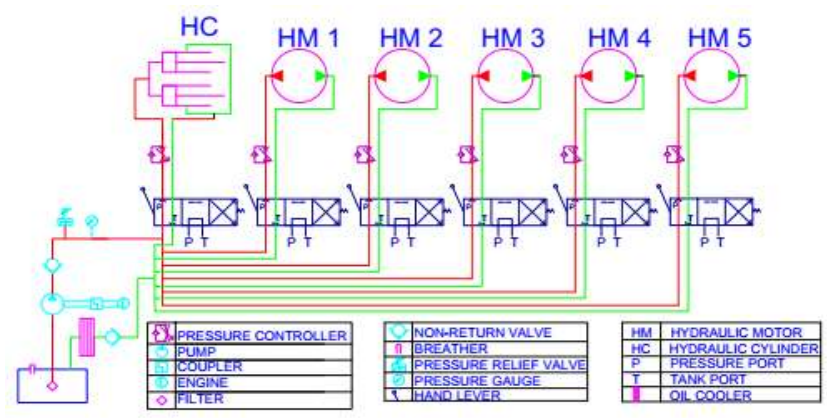

Fig. 1. Hydraulic system of pokkali paddy harvester

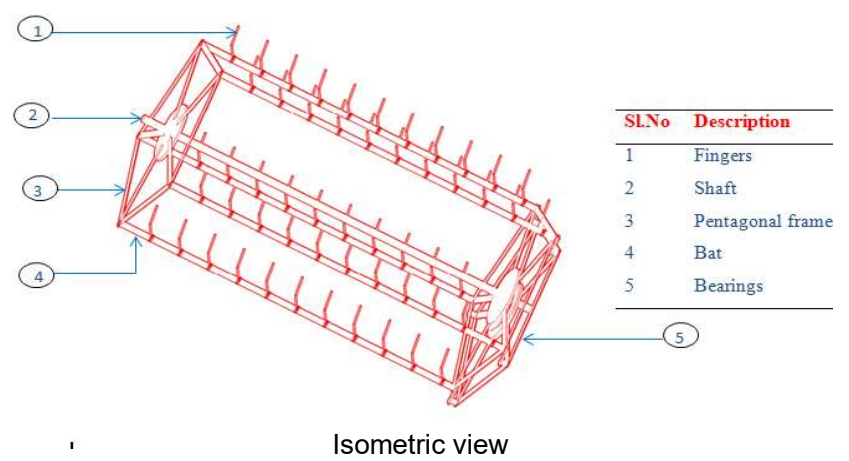

Fig. 2. Reel assembly

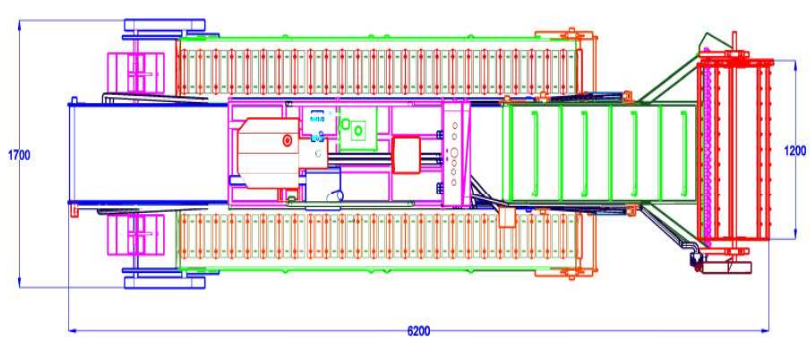

Fig. 3. Top view
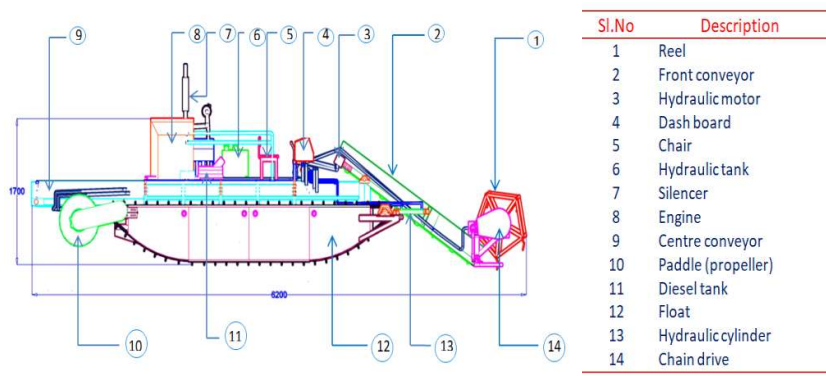

Fig. 4. Side view 
Table 1. Specifications of Pokkali paddy harvester

\begin{tabular}{ll}
\hline Parts & Specifications \\
\hline Overall dimensions & Length- $6.2 \mathrm{~m}$ \\
& Width- $1.7 \mathrm{~m}$ \\
& Height $-1.7 \mathrm{~m}$ \\
Float & Length $-3.0 \mathrm{~m}$ \\
& Width- $0.45 \mathrm{~m}$ \\
& Height - $0.60 \mathrm{~m}$ \\
Engine & 24 HP Diesel engine \\
Pump & Double acting hydraulic pump \\
Motors for conveyors and cutters & Hydraulic motors (M+S make) \\
Lift & Hydraulic cylinders \\
Conveyors & polypropylene \\
Fuel \& oil storage tanks & Fuel Tank - 40 litres; Oil Tank - 150 litres \\
Operator cabin & Comfortable seat with canopy storage boxes for tools, life jackets etc. \\
Controls & Hydraulic DC valves with levers for hand operation \\
Control panel & Ammeter, Voltmeter, RPM meter, Oil Pressure Gauge, Temperature gauge, Hour Meter, Light Switches \\
Transportation \& handling & Hooks provided for lifting and hauling \\
Finish & Epoxy - Corrosion resistant ; Colour - As per customer choice \\
Material for construction & Marine aluminum steel \\
\hline
\end{tabular}

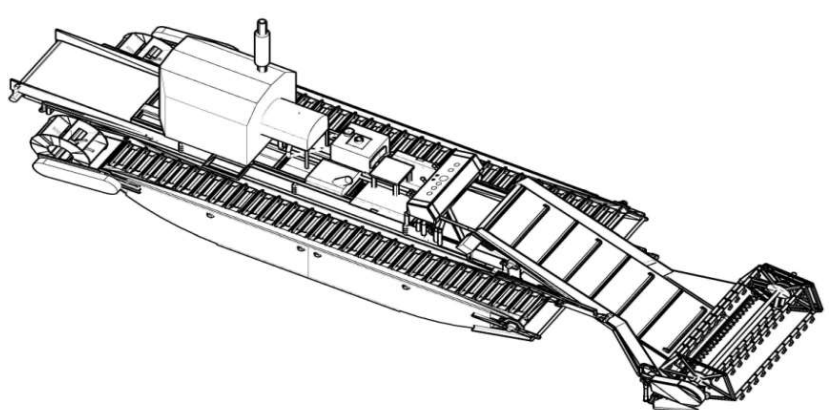

Fig. 5. Isometric view

hydraulic cylinders sufficient energy should be supplied. Hence, $24 \mathrm{hp}$ diesel engines have to be selected as the prime mover.

\section{RESULTS AND DISCUSSION}

The reel was designed for the Pokkali paddy harvester and index is 1.2 and pitch of reel is $30 \mathrm{~cm}$. The front conveyor designed for the Pokkali paddy. The overall dimension of conveyor was $1700 \times 600 \times 100 \mathrm{~mm}$ and $3 \mathrm{~mm}$ thickness polypropylene conveyor belt was selected to convey the cutting paddy stalk at operating speed of $0.47 \mathrm{~m} \mathrm{~s}^{-1}$. The centre conveyor was designed for the Pokkali paddy harvester. The overall size provided for conveyor was $3700 \mathrm{x}$ $600 \times 100 \mathrm{~mm}$. A thickness of $3 \mathrm{~mm}$ polypropylene conveyor belt was selected to convey and store of the cutting paddy stalk at operating speed of $0.416 \mathrm{~ms}^{-1}$. The capacity to meet the power requirement for harvesting is taken into consideration for the selection of the prime mower. The total weight of the Pokkali paddy harvester comes around 1700 $\mathrm{kg}$. In order to operate cutter bar, reel assembly, front conveyor, centre conveyor and float with hydraulic motors and then to lift the front conveyor with hydraulic cylinders sufficient energy should be supplied. Hence, $24 \mathrm{hp}$ diesel engines have to be selected as the prime mover.

\section{CONCLUSION}

In conventional method of pokkali paddy harvesting, manual harvesting using sharp sickles are practiced. For the harvesting, highly labour intensive, drudgery and more time consuming operations are required. The paddy cultivation goes on decreasing every year. Hence, there was a great demand for a suitable harvesting machine, especially for harvesting the paddy. The Pokkali paddy harvester was designed for harvest panicles (ear heads) of paddy crop. The harvester was operated by a hydraulic system. The total weight of the Pokkali paddy harvester comes around 1700 $\mathrm{kg}$. The overall dimension of the harvester is $6.2 \times 1.7 \times 1.7 \mathrm{~m}$ $(\mathrm{LxWxH})$.

\section{REFERENCES}

Abhilash Joseph E 2016. Rice cultivation in saline tracts of Kerala. International Journal of Fisheries and Aquatic Studies 4(4): 355358.

Ananth K, Vaitla Rakesh and Pothamsetty Kasi Visweswarao 2013. Design and selecting the proper conveyor-belt. International 
Journal of Advance Engineering Technology 4(2): 43-49.

Antony A, Mercy A and Shaju SS 2014. Effect of rotational Pokkali cultivation and Shrimp farming on the soil characteristics of two different Pokkali field at Chellanam and Kadamakudi, Kochi, Kerala. International Research Journal of Environmental Science 3(9): 61-64.

Arman Jalali and Reza Abdi 2014. The effect of ground speed, reel rotational speed and reel height in harvester losses. Journal of Agricultural and Sustainable 5(2): 221-231.

Bansal RK 2005. Fluid Mechanics and Hydraulic Machines. Nineth edition, Laxmi Publications (P) Ltd., New Delhi-110006, India.

Bawatharani R, Jayatissa DN, Dharmasena DA and Bandara 2013. Impact of Reel Index on header losses of paddy and performance of combine harvesters. Tropical Agricultural Research 25(1): 1-13

Ephrem Zeleke Kassa and Ing Zewdu Abdi 2014. Design and modification of appropriate reel mechanism to harvest tef crop. International Journal of Research in Mechanical Engineering 2(1): $15-25$

Gayathri R N and Raveendran K 2009. Exploration of untapped potentiality of coastal paddy fields of Kerala (India): A case study. Middle-East Journal Science Research 4(1): 44-47.

Giles RV, Evett JB and Liu C 1994. Fluid Mechanics and Hydraulics, McGraw-Hill, Singapore, p 58

Jayan PR and Sathyanathan N 2010. Overview of farming practices in the water-logged areas of Kerala, India. International Journal Agricultural \& Biological Engineering 3(4):1-16

Jignesh Vasava and Hitesh Raiyani 2016. Modeling and analysis of telescopic hydraulic cylinder for increase load capacity. International Journal for Science Research \& Development 4(3): 1125-1127.

Kepner RA, Roy Bainer, and Barger E L1978. Principles of Farm Machinery. CBS publishers and Distrubutors.

Omofunmi OE, Ebifemi SA and Eweina AB 2016. Design of water Hyacinth (Eichhornia crassipes) Harvester. Journal of Scientific Research\& Report10(5): 1-10.

Sasidharan NK, Abraham CT and Rajendran CG 2012. Spatial and temporal integration of rice, fish, and prawn in the coastal wetlands of central Kerala, India. Journal of Tropical Agricultural 50(2): 15-23.

Shamna N 2014. Study on farmers perception on prospects and problems of pokkali rice farming in the state of Kerala. Published MSc Thesis, Department of Agricultural Extension College of Agriculture, Acharya n. G. Ranga Agricultural University Rajendranagar, Hyderabad.

Sharma DN and Mukesh S 2008. Principles and problems, Farm Machinery Design. Jain brothers publications.

Srivastava AK, Goering CE and Rohrbach RP 1993. Engineering principles of agricultural machines. American Society of Agricultural Engineering 414-416.

Vanaja T 2013. KAIPAD: A unique, naturally organic, saline prone rice ecosystem of Kerala, India. American Journal of Environment Protection 2(2): 42-46.

Varshney AC, Tiwari PS, Suresh Narang and Mehta CR 2004. Data Book for Agricultural Machinery Design.Central Institute of Agricultural Engineering, Nabi bagh, Berasia road, Bhopal. 